Published in final edited form as:

Hepatology. 2002 November ; 36(5 0 1): S220-S225. doi:10.1053/jhep.2002.36811.

\title{
Alcohol Use and Hepatitis C
}

\author{
Marion G. Peters and Norah A. Terrault \\ Department of Gastroenterology, University of California, San Francisco, CA
}

\section{Abstract}

Excess alcohol consumption can worsen the course and outcome of chronic hepatitis C. It is important to distinguish between alcohol abuse, which must be treated on its own merits, and the effect of alcohol use on progression, severity, and treatment of hepatitis C. Most studies on the effects of alcohol on hepatitis $\mathrm{C}$ have focused on patients, with high levels of daily alcohol intake. Indeed, the adverse effects of light and moderate amounts of alcohol intake on hepatitis $\mathrm{C}$ virus (HCV) infection have not been clearly shown, and only limited studies have been performed. Sex differences exist in the effect of alcohol on fibrosis as well as on the severity of hepatitis C. Alcohol use has been reported to be associated with lower responses to therapy and, in some studies, higher HCV RNA levels and increased HCV quasi-species. Few studies address the treatment of hepatitis $\mathrm{C}$ in the alcoholic individual or determine the effect of continued light or moderate alcohol use on the outcome of treatment response. In summary, many critical questions remain regarding the interactions between alcohol and hepatitis C. Currently, the evidence from the literature shows that heavy alcohol intake worsens the outcome of HCV infection. The literature is inadequate to provide definitive recommendations regarding the effect of light to moderate alcohol use in patients with hepatitis $\mathrm{C}$.

Most studies of the effect of alcohol on hepatitis $\mathrm{C}$ have focused on persons who use 50 $\mathrm{g} / \mathrm{day}$ or more of alcohol. These levels represent heavy alcohol intake and are typical of alcohol abuse. Many patients presenting to their healthcare provider for management of hepatitis $\mathrm{C}$ have not used alcohol at these levels. As will be discussed, many of these patients stop drinking after learning of their diagnosis but request information about the effects of light to moderate alcohol use on progression of their liver disease. This review will discuss current knowledge about alcohol and hepatitis C: where there is consensus, where there is confusion, and where future research studies are needed.

\section{Alcohol and Fibrosis Progression in Hepatitis C Virus Infection}

High levels of excess alcohol intake worsen the course and outcome of chronic hepatitis C. ${ }^{1-3}$ Poynard et al. ${ }^{1}$ studied 1,574 patients with hepatitis $\mathrm{C}$ who had not received antiviral therapy but who had undergone liver biopsy and had an accurate history of alcohol intake. Alcohol consumption was assessed as none, moderate (0-49 g/day), and heavy (50 g/day or more). Irrespective of age or duration of infection, patients who drank more than $50 \mathrm{~g}$ daily 
had a $34 \%$ increased rate of progression of fibrosis over nondrinkers. The rate of progression of fibrosis in fibrosis units per year increased from 0.125 (95\% confidence interval [CI], $0.111-0.143$ ) in nondrinkers, to 0.143 (95\% CI, 0.118-0.160) in those drinking 0 to $49 \mathrm{~g} /$ day, to 0.167 (95\% CI, 0.133-0.174) in those drinking $50 \mathrm{~g} /$ day or more, suggesting a dose effect. However, associations between increased fibrosis progression and the lower amounts of alcohol intake were not statistically significant, and measurements of alcohol intake were not performed in a uniform, standardized manner. Overall, the relative risk for progression of fibrosis with heavier alcohol intake was 2.36 (95\% CI, 1.62-3.45; $P=.0001)$. The investigators validated this model in a second group of 1,037 hepatitis $\mathrm{C}$ virus (HCV)infected patients and again showed increased risk of fibrosis with heavy alcohol use $(P<$. 008).

\section{Alcohol, Cirrhosis, and Survival}

In a retrospective, cohort study, the HCV National Register Steering Group in the United Kingdom traced 924 patients who were infected with HCV after a blood transfusion and 475 transfusion-recipient controls. Patients had received at least one unit of blood that was positive for antibody to $\mathrm{HCV}$ and were assessed for alcohol intake using validated questionnaires an average of 10 or more years after transfusion ${ }^{4}: 274$ were teetotalers, 421 drank less than $30 \mathrm{~g} /$ day of alcohol, and 125 drank more than $30 \mathrm{~g} /$ day of alcohol. Factors associated with worse survival in both patients and controls were older age, male sex, and level of alcohol consumed $(P<.003) .{ }^{4}$ Compared with those who drank less than $20 \mathrm{U} / \mathrm{wk}$ ( $\sim 30 \mathrm{~g} /$ day), there was increased risk of fibrosis (relative risk [RR], 2.84) and lower survival $(\mathrm{RR}, 1.28)$ in those who drank more than $20 \mathrm{U} / \mathrm{wk}$ and in nondrinkers (RR, 1.97 for fibrosis; $\mathrm{RR}, 1.18$ for survival), but the differences in survival did not reach statistical significance.

The Dionysos study analyzed hepatitis virus markers, alcohol intake (assessed by questionnaires of daily and lifetime intake), and clinical and biochemical evidence of liver disease among 6,917 unselected residents of 2 cities in northern Italy. ${ }^{3}$ Of the 6,917 residents, $2.3 \%$ were $\mathrm{HCV}$ RNA positive and $62 \%$ admitted to drinking alcohol, of whom $21 \%$ drank more than $30 \mathrm{~g} /$ day. Both $\mathrm{HCV}$-negative and $\mathrm{HCV}$-positive subjects who drank more than $30 \mathrm{~g} /$ day of alcohol for more than 10 years had a 3-fold higher risk of cirrhosis (95\% CI, 1.2-7.4; $P<.01$ ). An alcohol intake less than $30 \mathrm{~g} /$ day did not increase the risk of clinically apparent cirrhosis, but histology was not assessed in most patients. Among HCVpositive individuals who drank more than $30 \mathrm{~g} /$ day of alcohol, $32 \%$ had cirrhosis compared with $10 \%$ of those who drank less. There were 5 cases of hepatocellular carcinoma (HCC), all in the heavier drinking group.

In another study of Italian patients, Corrao and Arico analyzed results from 2 hospital-based, case-control studies of $285 \mathrm{HCV}$-positive patients with cirrhosis and 417 hospitalized controls. ${ }^{5}$ A lifetime daily alcohol intake that averaged more than $50 \mathrm{~g}$ daily was associated with an increased risk of cirrhosis in both HCV-positive (RR, 26.1; 95\% CI, 8.7-78.2) and negative (RR, 4.5; 95\% CI, 2.1-9.3) subjects. The combination of HCV and alcohol had an additive effect on the risk of cirrhosis; however, at levels greater than $125 \mathrm{~g} /$ day of alcohol, the risks were synergistic (HCV-positive RR, 133; 95\% CI, 37.6-473; HCV-negative RR, $15 ; 95 \%$ CI, 7.1-514).

Hepatology. Author manuscript; available in PMC 2014 August 06. 
In the United States, 4 studies have evaluated cirrhosis, alcohol, and hepatitis $\mathrm{C}$ in detail. Harris et al. analyzed factors associated with cirrhosis among 206 patients who developed hepatitis $\mathrm{C}$ after transfusion and were followed up for an average of 15 years compared with a cohort of control patients who received transfusions but did not develop hepatitis C. ${ }^{6}$ Among those with hepatitis $\mathrm{C}, 17 \%$ developed cirrhosis compared with $2.8 \%$ of controls ( $P$ $<.001)$. The risk of cirrhosis was 4-fold increased among those who drank more than 80 g/day of alcohol (odds ratio [OR], 4.0, 95\% CI, 2.1-7.7). Wiley et al. analyzed factors associated with more advanced liver disease in a cohort of 176 patients who underwent liver biopsy for chronic hepatitis C. ${ }^{2}$ Alcohol intake of more than $80 \mathrm{~g}$ daily was associated with an increase in the estimated rate of fibrosis progression after 10 years of $\mathrm{HCV}$ infection and a higher rate of cirrhosis ( $56 \%$ vs. $22 \% ; P<.05$ ). Thomas et al. followed up 1,667 HCVpositive injection drug users for a median of 8.8 years in a community setting. ${ }^{7}$ In a multivariate model, alcohol increased the risk of development of end-stage liver disease as assessed clinically. The relative risk of end-stage liver disease was 3.60 (95\% CI, 1.73-7.52) for those drinking more than $260 \mathrm{~g} / \mathrm{wk}$ of alcohol, as assessed by standard questionnaires at semiannual visits. There was a significant trend from 0 with increasing amounts of alcohol consumed (RR, 1.57 for those drinking 13-37 $\mathrm{g}$ daily and 3.60 for those drinking more $[P<$. 002 for trend]). A fourth study from the United States evaluated the outcome of hospitalbased care of patients with liver disease due to hepatitis $\mathrm{C}$ and/or alcohol. ${ }^{8}$ Using diagnostic codes for hepatitis $\mathrm{C}$ and alcohol abuse, they identified 53,200 hospitalizations (36\% liverrelated) for patients with hepatitis $\mathrm{C}$ and 11,700 (63\% liver-related) for patients with both hepatitis $\mathrm{C}$ and alcohol abuse in 1995. An increased risk of death (OR, 1.4; 95\% CI, 1.2-1.5) was seen in patients with hepatitis $\mathrm{C}$ who also had alcohol abuse. The combination of hepatitis $\mathrm{C}$ and alcohol abuse was associated with younger age at hospitalization and higher rate of death compared with hepatitis $\mathrm{C}$ or alcoholic liver disease alone.

In a study from Japan, Khan and Yatsuhashi found higher degrees of fibrosis on liver biopsy specimens from patients with chronic hepatitis $\mathrm{C}$ who drank alcohol compared with those who did not after controlling for duration of disease, and this increase was seen with both heavy ( $80 \mathrm{~g}$ or more daily) and moderate $\left(<80 \mathrm{~g}\right.$ daily) alcohol intake. ${ }^{9}$ The risk of cirrhosis was 1.5 - to 2.3 -fold greater in drinkers than in nondrinkers $(P<.01)$. Further delineation of the effects of lower levels of alcohol intake was not assessed. In a study from Australia, HCV-positive patients with cirrhosis had a greater lifetime alcohol intake compared with those without cirrhosis $(P<.02) .{ }^{10} \mathrm{~A}$ recent study from Sweden retrospectively assessed moderate lifetime alcohol intake in 78 selected patients who had 2 liver biopsies performed a median of 6.3 years apart. ${ }^{11}$ All patients had daily alcohol consumption of less than $40 \mathrm{~g}$ daily. The amount of alcohol taken between the 2 biopsy specimens was evaluated by lifetime questionnaire. Patients with more progressive fibrosis had higher alcohol consumption (5.7 vs. $2.6 \mathrm{~g} / \mathrm{day} ; P=.03$ ), higher drinking frequency ( 34.5 vs. 8.2 days/yr; $P$ $=.006)$, and a higher quantity of alcohol consumed per occasion ( 4.0 vs. 3.0 drinks between biopsies; $P=\mathrm{NS}$ ). Those with progressive fibrosis were older at the time of the first biopsy and were followed up longer. The age differences were not statistically significant but may have been a significant confounder, because age was not controlled for in the analysis. These findings highlight the importance of careful alcohol questionnaires to evaluate pattern of drinking, lifetime use, and even type of alcoholic beverage consumed. 
In summary, multiple studies have shown increased fibrosis progression, rates of cirrhosis, and risk of death in patients with hepatitis $\mathrm{C}$ who have heavy alcohol intake. Only one study assessed patients drinking less than $40 \mathrm{~g}$ /day of alcohol. ${ }^{11}$ This single study was retrospective but found that fibrosis correlated with greater alcohol use and more frequent drinking. Unfortunately, most studies have evaluated the extremes of alcohol intake with little emphasis on alcohol intake of 1 to 2 drinks per day or less than $20 \mathrm{~g}$ daily. The 2 studies that analyzed relatively lower amounts of alcohol intake (cutoff of $30 \mathrm{~g} / \mathrm{day}$ ) found that alcohol intake at these levels worsened the rate of development of fibrosis in hepatitis $\mathrm{C}$, but the degree of worsening was not statistically significant. ${ }^{3,4}$

\section{Alcohol and HCC}

A relationship between heavy alcohol intake, $\mathrm{HCV}$, and $\mathrm{HCC}$ has been shown in a number of studies but mostly in studies from Japan and Italy. Excess alcohol intake was shown to predispose to the development of liver cancer in the Dionysos study. ${ }^{12}$ Studies from Japan ${ }^{13,14}$ reported an increased risk of HCC in patients with hepatitis $\mathrm{C}$ who were drinking more than $65 \mathrm{~g}$ daily for more than 5 years (RR, 3.04; 95\% CI, 1.31-7.09; $P<.01$ ). Kubo et al. compared tumor characteristics in patients with HCC and found that the tumors from heavy drinkers were more anaplastic (5\% had well-differentiated HCC compared with $45 \%$ of nondrinkers; $P<.001)$ with increased capsular, extracapsular, and portal vein invasion and intrahepatic metastases $(P<.05)$. The heavy drinkers with HCC also had a shortened survival $(P<.04) .{ }^{13}$ In a study from the United States, Wiley et al. found one HCC in 86 $\mathrm{HCV}$-infected patients who were nondrinkers compared with 4 of 90 patients with hepatitis $\mathrm{C}$ who were heavy drinkers. ${ }^{2}$ Thus, a number of studies have shown that heavy alcohol intake increases the risk of cirrhosis and liver cancer in hepatitis $\mathrm{C}$, but the role of light or moderate intake has not been adequately assessed.

\section{Alcohol, HCV, and Sex Differences}

There are limited studies on sex differences and the effect of alcohol on progression of HCV infection. Chronic hepatitis $\mathrm{C}$ is often histologically milder in women than men. In studies from Poynard et al., fibrosis progression per year was 0.154 (95\% CI, 0.143-0.167) for men and 0.111 (95\% CI, 0.100-0.125) for women. ${ }^{1}$ However, women may be more sensitive to the adverse effects of alcohol and experience ill effects of alcohol at a lower level of intake. The population-based Dionysos study found the risk of cirrhosis was twice as high in women as in men with the same amount of alcohol intake. ${ }^{3,15}$ Wiley et al. found no difference in rates of cirrhosis by sex but used a lower threshold of alcohol consumption for women (40 g daily) compared with men ( $60 \mathrm{~g}$ daily). They did not assess the rate of fibrosis progression between sexes for the same amount of alcohol ingested but suggested that lower amounts of alcohol were required for the increased risk of fibrosis progression in women with chronic hepatitis $\mathrm{C}$. Thus, there is indirect weak evidence that women with hepatitis $\mathrm{C}$ are more susceptible than men to the adverse hepatic effects of alcohol.

\section{Alcohol and Treatment of Hepatitis C}

Ongoing alcohol consumption has been reported to decrease the rate of response to antiviral therapy of hepatitis C. Alcohol may affect the outcome of therapy by decreasing adherence 
or interfering with the antiviral actions of interferon-based therapy. Interferon acts both as an antiviral agent and an immune modulator (enhancer). Alcohol is known to blunt immune responses, but its effects on interferon actions have not been well defined. Virtually all large trials of therapy of hepatitis $\mathrm{C}$ have excluded persons who have a recent history of alcohol abuse and usually required a 1- to 2-year period of abstinence before therapy was initiated. However, the need for, or length of, a period of abstinence before starting antiviral therapy has never been studied in a randomized, controlled manner. Moreover, concurrent alcohol use may limit individuals from being considered for treatment, and not all individuals who consume alcohol will comply with recommendations to stop drinking. Muir and Provenzale ${ }^{16}$ reported that among U.S. veterans with HCV infection being evaluated for treatment, $62 \%$ were drinking and $44 \%$ exhibited "hazardous" drinking patterns using the Alcohol Use Disorders Identification Test. ${ }^{17,18}$ Cromie et al. described 45 patients from Australia: 22 drinking less than $10 \mathrm{~g}$ and 23 drinking 30 to $100 \mathrm{~g}$ of alcohol daily. ${ }^{19}$ All were counseled to stop drinking, and half of the heavier drinkers did so. In the group who stopped drinking for 3 months, the mean serum alanine aminotransferase levels decreased from 269 to $144 \mathrm{IU} / \mathrm{L}$ and mean HCV RNA from 2.6 to 0.42 million genome equivalents per milliliter. Two studies from Italy showed that up to two thirds of patients were drinking alcohol when first diagnosed with hepatitis, and only one third to one half stopped drinking when counseled to stop. ${ }^{20,21}$

Treatment studies in patients continuing alcohol use are limited. Loguercio et al. found that the response of 65 patients treated with interferon was inversely proportional to the amount of alcohol ingested, using cutoff values of 40 and $80 \mathrm{~g}$ of alcohol daily. ${ }^{21}$ Ohnishi et al. studied 60 Japanese patients whose alcohol intake was 23 to $70 \mathrm{~g}$ (moderate) or more than $70 \mathrm{~g}$ (heavy) daily. ${ }^{22}$ All moderate drinkers abstained for $39 \pm 18$ months before and during therapy, and one half of the heavier drinkers abstained for $39 \pm 37$ months. The response to therapy was similar between infrequent drinkers and moderate drinkers (28\% and $25 \%$ ) but less in the heaviest drinkers: $16 \%$ in those who abstained $38 \pm 37$ months before and during therapy and $0 \%$ in those heaviest drinkers who abstained during therapy only. These differences were significant between infrequent drinkers and those who drank heavily until the time of treatment $(P<.05)$, suggesting that a sustained period of abstinence improved the response to antiviral therapy. Okazaki et al. found similar results in another small group of 39 Japanese patients who abstained for 1 month before, during, and for 1 month after interferon therapy. ${ }^{23}$ Sustained virological responses were achieved in $53 \%$ of 15 nondrinkers, $43 \%$ of 14 patients who drank less than $70 \mathrm{~g} /$ day of alcohol, and none of the 10 patients who drank more than $70 \mathrm{~g} /$ day. A recent study from Italy described 150 consecutive patients with hepatitis $\mathrm{C}$ who abstained from alcohol for 6 months, continued to have elevated serum alanine aminotransferase levels, and were treated with interferon alfa thrice weekly. ${ }^{24}$ The sustained virological response rate was $33 \%$ in nondrinkers, $20 \%(P=\mathrm{NS})$ in those who drank 25 to $50 \mathrm{~g} /$ day of alcohol, and $9 \%(P<.02)$ in those who drank more than $75 \mathrm{~g} /$ day. There was no difference in nonresponders but an increase in relapsers (moderate drinkers, $52 \% ; P<.05$; heavy drinkers, $59 \% ; P<.01)$ over nondrinkers $(36 \%)$. In multivariate logistic regression analysis for nonresponse to interferon therapy, genotype 1 was the most important predictor (OR, 5.94; 95\% CI, 4.72-7.26) and then age (OR, 1.07; 95\% CI, 1.02-1.7) and previous alcohol intake (OR, 1.03; 95\% CI, 1.01-1.05). Abstinence 
was high (>98\%) as assessed by carbohydrate-deficient transferrin. HCV RNA levels were higher in heavy drinkers in this study. This study showed that previous alcohol intake adversely affected treatment of hepatitis $C$ and that 6 months of abstinence did not offset this effect.

Although studies have included only small numbers of patients treated for hepatitis $\mathrm{C}$, a proportion of patients continued drinking and the ultimate response rate correlated inversely with the level of alcohol intake during therapy. Once again, as in fibrosis studies, antiviral treatment studies focused on persons with a high daily intake of alcohol, without information on patients drinking 10 to $20 \mathrm{~g} /$ day of alcohol. Current evidence is strong that continued heavy alcohol intake during therapy adversely affects the response to treatment. Both counseling and monitoring before and during therapy is needed to aid patients in decreasing or stopping alcohol ingestion. The mechanism of the decreased response rate in patients using alcohol has not been defined.

Interferon alfa therapy has also been reported to increase the rate of recidivism among persons with a history of alcohol abuse or dependence. The effect of interferon therapy on relapse of alcoholism has not been studied prospectively. In the study by Tabone et al., ${ }^{24}$ few previously alcoholic patients experienced a relapse while on therapy. However, the depression, irritability, and anxiety that occurs in $20 \%$ to $30 \%$ of patients treated with interferon-based therapies may be difficult for the patient with a recent history of alcohol dependence and predispose to recidivism.

\section{Alcohol and HCV RNA}

The available literature on the effects of alcohol on viral replication and serum HCV RNA levels is conflicting. Some studies have shown that alcohol intake is associated with higher levels of HCV RNA, ${ }^{1,21,25}$ but the actual increase was modest. Other studies have not found a difference in HCV RNA levels related to alcohol intake. ${ }^{2,3,9}$ Careful prospective assessment of larger cohorts of patients followed up over time would better answer the effect of alcohol on viral replication. An increase in HCV quasispecies has been reported associated with heavy drinkers (>70 g/day) compared with nondrinkers. ${ }^{26,27}$ The effects of light or moderate alcohol intake on viral replication and evolution of quasi-species deserves evaluation in a prospective controlled fashion.

\section{Future Research Needs}

Although the deleterious effects of heavy daily alcohol intake on the course of chronic hepatitis $\mathrm{C}$ seem to be incontrovertible, the effects of lesser amounts of alcohol are unclear and require further study (Table 1). Patients with a history of alcohol abuse or dependence should be asked to be abstinent for a period before starting therapy and need to be supported by professional counseling and close monitoring during therapy. Patients with alcoholism should be treated for this condition, independent of the need for treatment of coexisting hepatitis $\mathrm{C}$. This includes abstinence and rehabilitation. At the present time, there is no reason to withhold antiviral therapy for chronic hepatitis $\mathrm{C}$ from the patient with a history of alcoholism who remains abstinent as long as adequate support can be provided during therapy. For the patient with hepatitis $\mathrm{C}$ without alcoholism, abstinence seems to be prudent 
while receiving a course of interferon-based therapy, but light to moderate alcohol intake should not be an exclusion criteria for treatment of hepatitis $\mathrm{C}$ and a period of abstinence before starting therapy should not be enforced.

Future research should be aimed at assessment of the effects of light and moderate drinking on the virological features, immune reactivity, natural history, and treatment outcomes of persons with hepatitis $\mathrm{C}$. Additionally, research on methods to enhance compliance with alcohol abstinence (when this is recommended) and management of alcohol use and abuse in patients with hepatitis $\mathrm{C}$ is important (Table 2). Future research would benefit from the use of validated instruments to measure alcohol intake in larger numbers of patients, followed up for longer periods of time, and with careful histological documentation of disease to better define the effects of moderate alcohol intake on chronic hepatitis $\mathrm{C}$ and the need for abstinence before and during therapy.

\section{Acknowledgments}

Dr. Peters is supported in part by grants from the National Institute on Alcohol Abuse and Alcoholism (R01 AA12879). Dr. Peters has received research grants from Hoffmann-La Roche, Schering-Plough Research Institute, Ortho Biotech, and Gilead Sciences. Dr. Peters has served as a paid lecturer for Schering Corp., Gilead Sciences, Roche Pharmaceuticals, and Amgen Inc.

Dr. Terrault is supported in part by grants from the Centers for Disease Control and Prevention (U50 CCU915651), the National Institute of Diabetes and Digestive and Kidney Diseases (U01 DK60346), and the National Institute on Alcohol Abuse and Alcoholism (R01 AA12879). Dr. Terrault is a consultant to or has received research grants from Schering-Plough Research Institute, Hoffmann-La Roche, InterMune Inc., STL Biopharmaceuticals, and Bayer Diagnostics.

\section{Abbreviations}

CI confidence interval

HCV hepatitis $\mathrm{C}$ virus

RR relative risk

HCC hepatocellular carcinoma

OR odds ratio

\section{References}

1. Poynard T, Bedossa P, Opolon P. Natural history of liver fibrosis progression in patients with chronic hepatitis C. The OBSVIRC, METAVIR, CLINIVIR, and DOSVIRC groups. Lancet. 1997; 349:825-832. [PubMed: 9121257]

2. Wiley TE, McCarthy M, Breidi L, Layden TJ. Impact of alcohol on the histological and clinical progression of hepatitis C infection. Hepatology. 1998; 28:805-809. [PubMed: 9731576]

3. Bellentani S, Pozzato G, Saccoccio G, Crovatto M, Croce LS, Mazzoran L, Masutti F, et al. Clinical course and risk factors of hepatitis $\mathrm{C}$ virus related liver disease in the general population: report from the Dionysos study. Gut. 1999; 44:874-880. [PubMed: 10323892]

4. Harris HE, Ramsay ME, Andrews N, Eldridge KP. Clinical course of hepatitis C virus during the first decade of infection: cohort study. BMJ. 2002; 324:450-453. [PubMed: 11859045]

5. Corrao G, Arico S. Independent and combined action of hepatitis $\mathrm{C}$ virus infection and alcohol consumption on the risk of symptomatic liver cirrhosis. Hepatology. 1998; 27:914-919. [PubMed: 9537428]

Hepatology. Author manuscript; available in PMC 2014 August 06. 
6. Harris DR, Gonin R, Alter HJ, Wright EC, Buskell ZJ, Hollinger FB, Seeff LB. The relationship of acute transfusion-associated hepatitis to the development of cirrhosis in the presence of alcohol abuse. Ann Intern Med. 2001; 134:120-124. [PubMed: 11177315]

7. Thomas DL, Astemborski J, Rai RM, Anania FA, Schaeffer M, Galai N, Nolt K, et al. The natural history of hepatitis C virus infection: host, viral, and environmental factors. JAMA. 2000; 284:450 456. [PubMed: 10904508]

8. Kim WR, Gross JB Jr, Poterucha JJ, Locke GR III, Dickson ER. Outcome of hospital care of liver disease associated with hepatitis $C$ in the United States. Hepatology. 2001; 33:201-206. [PubMed: 11124837]

9. Khan KN, Yatsuhashi H. Effect of alcohol consumption on the progression of hepatitis $\mathrm{C}$ virus infection and risk of hepatocellular carcinoma in Japanese patients. Alcohol Alcohol. 2000; 35:286295. [PubMed: 10869250]

10. Ostapowicz G, Watson KJ, Locarnini SA, Desmond PV. Role of alcohol in the progression of liver disease caused by hepatitis C virus infection. Hepatology. 1998; 27:1730-1735. [PubMed: 9620350]

11. Westin J, Lagging LM, Spak F, Aires N, Svensson E, Lindh M, Dhillon AP, et al. Moderate alcohol intake increases fibrosis progression in untreated patients with hepatitis $\mathrm{C}$ virus infection. $\mathrm{J}$ Viral Hepat. 2002; 9:235-241. [PubMed: 12010513]

12. Donato F, Tagger A, Gelatti U, Parrinello G, Boffetta P, Albertini A, Decarli A, et al. Alcohol and hepatocellular carcinoma: the effect of lifetime intake and hepatitis virus infections in men and women. Am J Epidemiol. 2002; 155:323-331. [PubMed: 11836196]

13. Kubo S, Kinoshita H, Hirohashi K, Tanaka H, Tsukamoto T, Shuto T, Kuroki T. High malignancy of hepatocellular carcinoma in alcoholic patients with hepatitis C virus. Surgery. 1997; 121:425429. [PubMed: 9122873]

14. Aizawa Y, Shibamoto Y, Takagi I, Zeniya M, Toda G. Analysis of factors affecting the appearance of hepatocellular carcinoma in patients with chronic hepatitis C. A long term follow-up study after histologic diagnosis. Cancer. 2000; 89:53-59. [PubMed: 10897000]

15. Bellentani S, Saccoccio G, Costa G, Tiribelli C, Manenti F, Sodde M, Saveria Croce L, et al. The Dionysos Study Group. Drinking habits as cofactors of risk for alcohol induced liver damage. Gut. 1997; 41:845-850. [PubMed: 9462221]

16. Muir AJ, Provenzale D. A descriptive evaluation of eligibility for therapy among veterans with chronic hepatitis C virus infection. J Clin Gastroenterol. 2002; 34:268-271. [PubMed: 11873110]

17. Conigrave KM, Saunders JB, Reznik RB. Predictive capacity of the AUDIT questionnaire for alcohol-related harm. Addiction. 1995; 90:1479-1485. [PubMed: 8528033]

18. Conigrave KM, Hall WD, Saunders JB. The AUDIT questionnaire: choosing a cut-off score. Alcohol Use Disorder Identification Test. Addiction. 1995; 90:1349-1356. [PubMed: 8616463]

19. Cromie SL, Jenkins PJ, Bowden DS, Dudley FJ. Chronic hepatitis C: effect of alcohol on hepatitic activity and viral titre. J Hepatol. 1996; 25:821-826. [PubMed: 9007708]

20. Pessione F, Degos F, Marcellin P, Duchatelle V, Njapoum C, Martinot-Peignoux M, et al. Effect of alcohol consumption on serum hepatitis $\mathrm{C}$ virus RNA and histological lesions in chronic hepatitis C. Hepatology. 1998; 27:1717-1722. [PubMed: 9620348]

21. Loguercio C, Di Pierro M, Di Marino MP, Federico A, Disalvo D, Crafa E, Tuccillo C, et al. Drinking habits of subjects with hepatitis $\mathrm{C}$ virus-related chronic liver disease: prevalence and effect on clinical, virological and pathological aspects. Alcohol Alcohol. 2000; 35:296-301. [PubMed: 10869251]

22. Ohnishi K, Matsuo S, Matsutani K, Itahashi M, Kakihara K, Suzuki K, Ito S, et al. Interferon therapy for chronic hepatitis $\mathrm{C}$ in habitual drinkers: comparison with chronic hepatitis $\mathrm{C}$ in infrequent drinkers. Am J Gastroenterol. 1996; 91:1374-1379. [PubMed: 8677998]

23. Okazaki T, Yoshihara H, Suzuki K, Yamada Y, Tsujimura T, Kawano K, Yamada Y, et al. Efficacy of interferon therapy in patients with chronic hepatitis C. Comparison between nondrinkers and drinkers. Scand J Gastroenterol. 1994; 29:1039-1043. [PubMed: 7871371]

24. Tabone M, Sidoli L, Laudi C, Pellegrino S, Rocca G, Della Monica P, Fracchia M, et al. Alcohol abstinence does not offset the strong negative effect of lifetime alcohol consumption on the outcome of interferon therapy. J Viral Hepat. 2002; 9:288-294. [PubMed: 12081606] 
25. Romero-Gomez M, Grande L, Nogales MC, Fernandez M, Chavez M, Castro M. Intrahepatic hepatitis $\mathrm{C}$ virus replication is increased in patients with regular alcohol consumption. Dig Liver Dis. 2001; 33:698-702. [PubMed: 11785717]

26. Sherman KE, Rouster SD, Mendenhall C, Thee D. Hepatitis cRNA quasispecies complexity in patients with alcoholic liver disease. Hepatology. 1999; 30:265-270. [PubMed: 10385665]

27. Takahashi K, Takahashi T, Takahashi S, Watanabe K, Boku S, Matsui S, et al. Difference in quasispecies of the hypervariable region 1 of hepatitis $\mathrm{C}$ virus between alcoholic and nonalcoholic patients. J Gastroenterol Hepatol. 2001; 16:416-423. [PubMed: 11354280] 


\section{Table 1}

\section{Alcohol and HCV Infection}

Heavy alcohol use (more than $50 \mathrm{~g}$ dally) worsens fibrosis

Increases risk of cirrhosis

Increases risk of HCC

Present data suggest that ingestion of more than $30 \mathrm{~g} /$ day of alcohol is harmful in persons with chronic hepatitis $\mathrm{C}$

Lower levels of alcohol intake may apply to women

Heavy alcohol intake ( $>50 \mathrm{~g}$ daily) during therapy leads to lower response rates to antiviral therapy

Cessation of heavy alcohol intake improves response to antiviral therapy

Alcoholic patients may be able to complete therapy but seem less responsive; abstinence from alcohol is recommended during therapy 
Table 2

Questions for Future Research on Alcohol and HCV Infection

What are the effects of different levels of alcohol intake on HCV RNA levels, quasi-species evolution, immune reactivity to HCV antigens, and biochemical and histological features of disease?

Is there a safe level of alcohol intake in patients with HCV infection?

What is the long-term histologic outcome of light or moderate drinkers with chronic hepatitis $\mathrm{C}$ ?

Can and should alcoholic patients be treated with interferon-based therapies?

What are the effects of light or moderate alcohol intake on interferon actions as well as side effects of interferon therapy?

How should patients with alcohol intake or alcoholism be supported and monitored during interferon therapy? 